\title{
Failed shoulder stabilization procedure in the elderly: reverse shoulder replacement is the treatment ultimum
}

\author{
Subramanian Kanthalu Narayanan, Navaladi Muthusamy, Vanaj Kumar Pauldhurai*
}

Department of Orthopaedics, Velammal Medical College Hospital and Research Institute, Madurai, Tamil Nadu, India

Received: 09 May 2019

Accepted: 05 July 2019

\section{*Correspondence:}

Dr. Vanaj Kumar Pauldhurai,

E-mail: drvanaj@gmail.com

Copyright: () the author(s), publisher and licensee Medip Academy. This is an open-access article distributed under the terms of the Creative Commons Attribution Non-Commercial License, which permits unrestricted non-commercial use, distribution, and reproduction in any medium, provided the original work is properly cited.

\begin{abstract}
Shoulder instability, though often seen in younger individuals it can also occur in the elderly. Shoulder instability in the elderly is often missed and definitive management gets delayed. Treatment delay has a significant influence on the choice of surgical procedure and its functional outcome. We report a 77 year old female who presented with a missed anterior dislocation of the glenohumeral joint. She had undergone an open Latarjet procedure for shoulder instability eight months before her presentation. Considering her age, humeral head bone defects, rotator cuff tear and degenerative changes in the joint we opted for a Reverse Shoulder Replacement in her. The patient now has a pain free, stable and mobile shoulder joint. Her pre-operative Constant score was 11 which improved to 67 at 6 months follow up. Now after 12 months follow up, she has active flexion up to $150^{\circ}$, abduction- $90^{\circ}$, external rotation- $10^{\circ}$, internal rotation- $30^{\circ}$ and extension- $50^{\circ}$. Reverse shoulder replacement is a viable treatment option for chronic locked shoulder dislocations with concomitant rotator cuff lesions. Though there is a concern about failure of the glenoid component due to bone defects, RSA is still preferable in elderly patients with low functional demand.
\end{abstract}

Keywords: Latarjet procedure, Rotator cuff insufficiency, Reverse shoulder replacement, Chronic shoulder dislocation, Failed Latarjet

\section{INTRODUCTION}

Shoulder instability is defined as a loss of ability for the soft tissue and bony structures to provide adequate restraints to keep the humeral head centered in the glenoid. ${ }^{1-3}$ Soft tissue restraints can be viewed as static and dynamic stabilizers. Static stability is provided by the inferior glenohumeral labro ligamentous complex and dynamic stability by the Rotator cuff muscles. Failure of either or both of these occurs in Shoulder instability. In a young person as the cuff muscles are strong, a dislocation ruptures the static stabilisers and spares the rotator cuff or only does a partial damage. But in the elderly, it is common to see a rotator cuff rupture during dislocation. If the bony attachment of the static stabilizer gets injured and if the fracture involves more than $25 \%$ of the total glenoid width, then the shoulder loses bony containment.
While considering intervention to regain stability it is essential to reproduce the lost anatomy. In case of isolated antero inferior labral tear and minimal bone loss Arthroscopic repair of the damaged tissue is sufficient. ${ }^{3,4}$ Arthroscopic soft tissue repair has higher failure rates if the glenoid bone loss is significantly high. ${ }^{5,6}$ For glenoid bone defects between 20 and $30 \%$ a bony procedure to regain the bony congruity is done. Coracoid process along with its muscular attachment can be transferred to the defective glenoid area to restore bony anatomy. 7,8 Success of this procedure is dependent on the surgeon's technical skills in proper screw positioning to ensure adequate coracoid fixation. If this procedure fails, a revision stabilization procedure using iliac crest bone graft can be performed to restore the bony congruity. In a situation of chronic dislocation, with ensuing destruction of articular surface and rotator cuff insufficiency, these 
bony procedures cannot give a good outcome. Here comes the role of reverse shoulder replacement which simultaneously addresses all the three issues, i.e., instability, arthritis and rotator cuff insufficiency. ${ }^{9,10}$.

\section{CASE REPORT}

Our patient is a 77 year old female, right hand dominant person who presented to us with pain and restricted movements of the right shoulder for past one year. She had undergone an open Latarjet procedure eight months before presentation for recurrent instability of the right shoulder. On examination, she had a healed delto pectoral scar and loss of normal shoulder contour with prominent Acromion. Her active range of movements were $20^{\circ}$ abduction, $20^{\circ}$ flexion, $10^{\circ}$ external rotation and $0^{\circ}$ internal rotation. Deltoid muscle contraction could be felt on resisted abduction. She had a passive flexion and abduction upto $60^{\circ}$ which was painful. X-ray of the right shoulder AP view (Figure 1), CT (Figure 2) and MRI (Figure 3) scans were done. The radiological findings were: antero inferior dislocation of the right shoulder with engaging anteromedial defect in the head of humerus (reverse Hillsach's lesion), $1.9 \mathrm{~cm}$ wide and 1.3 $\mathrm{cm}$ deep Hillsach's lesion, $2 \times 1.5 \mathrm{~cm}$ graft fixed to antero inferior glenoid rim, Bigliani type-i acromion, AC joint degeneration and rotator cuff tear with $2.5 \mathrm{~cm}$ retraction.

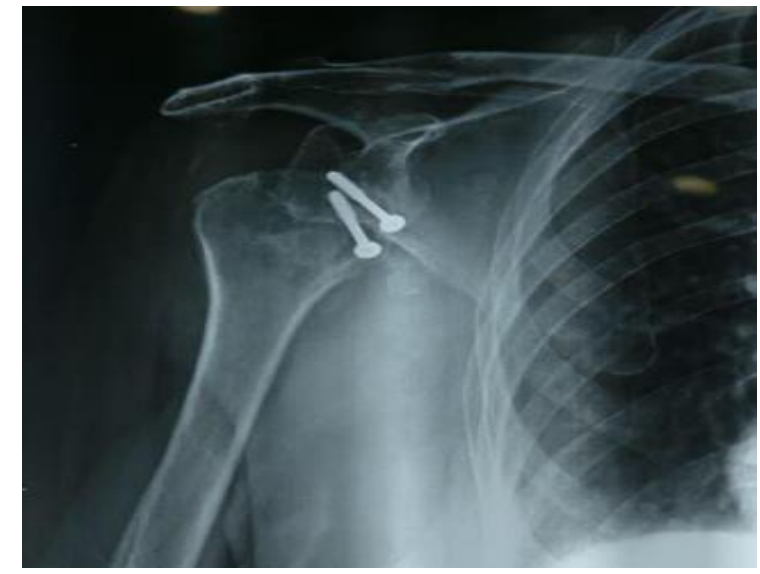

Figure 1: Pre-operative X-ray.

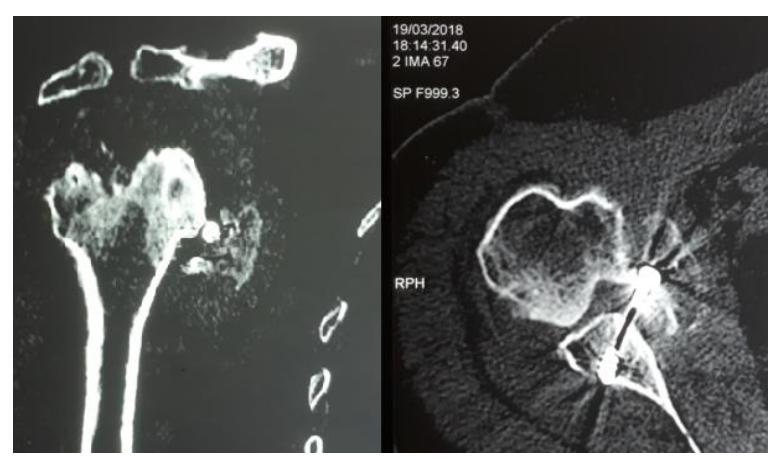

Figure 2: Pre-operative CT.
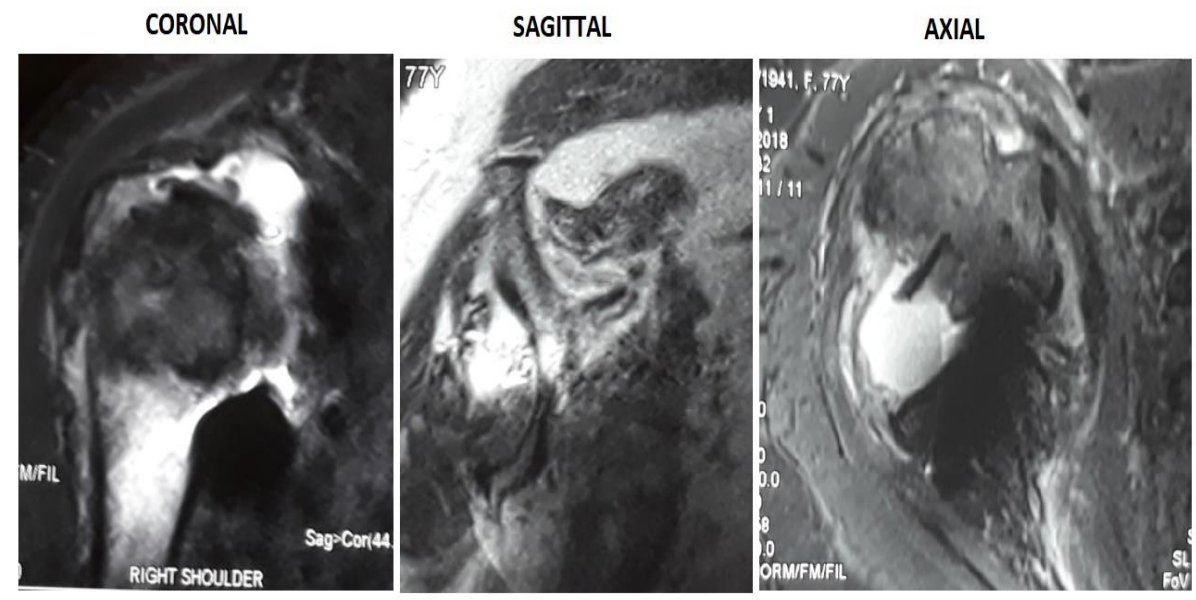

Figure 3: Pre-operative MRI.

Considering her age, rotator cuff status, complexity of the bone defects and degenerative changes we opted for a reverse shoulder replacement.

She was operated under general anaesthesia, in beach chair position, through deltopectoral approach. The humeral head was found locked anteriorly over the glenoid. Diffuse cartilage loss was observed on both the glenoid surface and the humeral head with significant humeral head bone loss. We used an Equinoxe reverse system (Exactech) prosthesis. After bony preparation a 36 mm glenosphere with $4 \mathrm{~mm}$ lateralization was fixed with $10^{\circ}$ inferior tilt. The humerus was cut in $20^{\circ}$ of retroversion, and a regular press fit stem was fixed into the humeral canal. A constrained liner was then implanted and final reduction done. The stability and range of movements were satisfactory. The postoperative X-ray showed good positioning and alignment of the implants (Figure 4). The patient was followed up regularly and progressive physiotherapy was continued till 6 months postoperatively. 


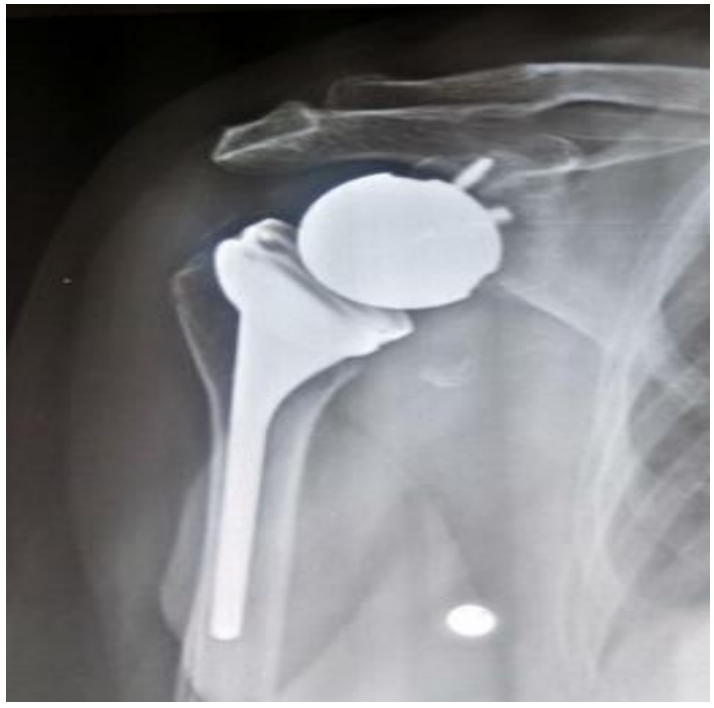

Figure 4: Post-operative X-ray.

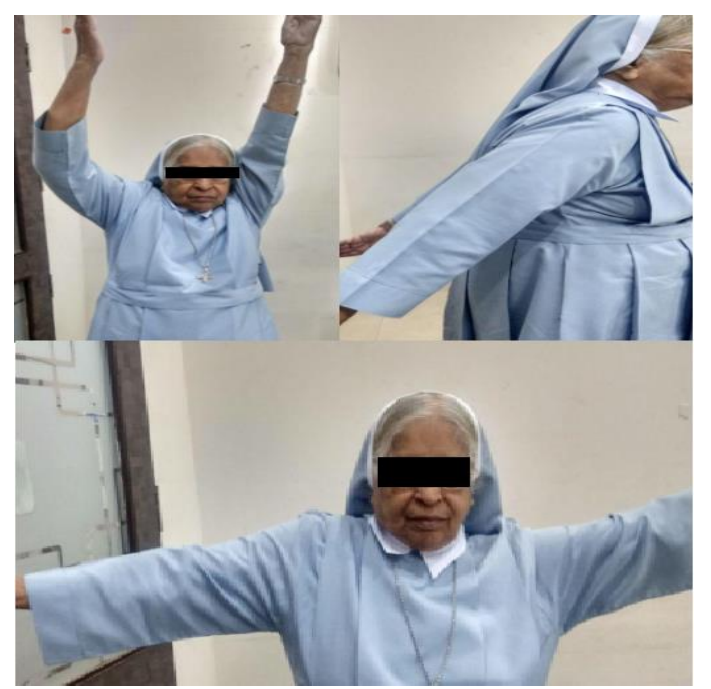

Figure 5: Range of movements at 12 months follow up.

The patient's pre-operative constant shoulder score was 11 and it improved to 67 at 6 months follow up. Now after 12 months follow up, she has active flexion up to $150^{\circ}$, abduction- $90^{\circ}$, external rotation- $10^{\circ}$, internal rotation- $30^{\circ}$ and extension- $50^{\circ}$ (Figure 5). She is now happy with a stable, pain free and mobile joint.

\section{DISCUSSION}

Unreduced anterior dislocations are poorly tolerated because the arm is fixed in abduction and external rotation away from the body, limiting access to the face/body. ${ }^{11}$ Multiple complications can occur following surgery to treat glenohumeral instability, including recurrent instability, stiffness, arthritis, loose or prominent implants, nerve injury and infection. Recurring instability, after shoulder stabilization surgery can be avoided by proper preoperative planning and choosing the right procedure. Common example is recurrent instability after anterior soft tissue repair rather than a bony procedure when there is bone loss. ${ }^{10}$ Despite doing a bony procedure, if the dynamic stabilizer (rotator cuff) is not functioning or there is resorption of coracoid graft then the dislocation will recur.

Our patient already had a rupture of the rotator cuff, and hence the dynamic stabilizer wasn't functioning causing the shoulder to dislocate again. ${ }^{12}$ Moreover the shoulder dislocation was not recognised immediately as the pain was assumed to be occurring due to the initial surgery. Moreover, when it was recognised, the attending physician was unsure of how to deal with it and the patient had taken a longer time to reach the appropriate centre. The delay in management had resulted in soft tissue contractures, significant wear and degeneration of glenoid margins and articular cartilage.

Patients with failed Latarjet, chronic shoulder dislocation, cartilage destruction in gleno humeral joint and rotator cuff insufficiency present a complex and challenging situation for the surgeon. The strategy in managing such complex situation involves addressing all the three problems, i.e., rotator cuff insufficiency, chronic instability and glenohumeral arthritis.

Reverse shoulder replacement is an established procedure to restore both stability and function in cuff-deficient shoulders. Long standing anterior glenohumeral dislocation results in both humeral and glenoid bone loss, as well as degenerative changes in the articular surface. If the glenoid vault is destroyed significantly, it may need bone grafting in order to fix the glenoid component. ${ }^{13}$ In our patient, as the coracoid graft had incorporated well, the space available for affixing the metaglene was sufficient and hence did not need an additional bone graft. Reverse shoulder replacement provides restores stability and function as it compensates the loss of rotator cuff by activating deltoid. Hence it remains the ideal option for a complex problem like this.

\section{CONCLUSION}

Chronic missed glenohumeral dislocation after bony procedure with rotator cuff insufficiency in elderly is challenging. Reverse Shoulder Replacement is a viable treatment option for chronic locked shoulder dislocations with concomitant rotator cuff lesions. Though there is a concern about failure of the glenoid component due to bone defects, reverse shoulder replacement is still preferable in elderly patients with low functional demand.

Funding: No funding sources

Conflict of interest: None declared

Ethical approval: Not required

\section{REFERENCES}

1. Jawa A, Riccheti E. In: Court-Brown C, Heckman J, McQueen M, RicciW, Tornetta III P (eds). 
Rockwood and Green's Fractures in Adults. 8th edition. Philadelphia: Wolters Kluwer Health; 2015: 1503-1566.

2. Stefko JM, Tibone JE, Cawley PW, ElAttrache NE, McMahon PJ. Strain of the anterior band of the inferior glenohumeral ligament during capsule failure. J Shoulder Elb Surg. 1997;6:473-9.

3. Yamamoto N, Muraki T, Sperling JW, Steinmann SP, Cofield RH, Itoi E, et al. Stabilizing mechanism in bone-grafting of a large glenoid defect. J Bone Joint Surg Am. 2010;92:2059-66.

4. Burkhart SS, De Beer JF. Traumatic glenohumeral bone defects and their relationship to failure of arthroscopic Bankart repairs: significance of the inverted-pear glenoid and the humeral engaging Hill-Sachs lesion. Arthroscopy. 2000;16:677-94.

5. Moroder P, Schulz E, Mitterer M, Plachel F, Resch $\mathrm{H}$, Lederer S. Long-term outcome after pectoralis major transfer for irreparable anterosuperior rotator cuff tears. J Bone Joint Surg Am. 2017;99:239-45.

6. Shin SJ, Kim RG, Jeon YS, Kwon TH. Critical value of anterior glenoid bone loss that leads to recurrent glenohumeral instability after arthroscopic Bankart repair. Am J Sports Med. 2017;45(9):197581.

7. Bessiere C, Trojani C, Pelegri C, Carles M, Boileau P. Coracoid bone block versus arthroscopic Bankart repair: a comparative paired study with 5-year follow-up. Orthop Traumatol Surg Res. 2013;99:123-30.

8. Waterman BR, Chandler PJ, Teague E, Provencher MT, Tokish JM, Pallis MP. Short-term outcomes of glenoid bone block augmentation for complex anterior shoulder instability in a high-risk population. Arthroscopy. 2016;32:1784-90.

9. Statz JM, Schoch BS, Sanchez-Sotelo J, Sperling JW, Cofield RH. Shoulder arthroplasty for locked anterior shoulder dislocation: a role for the reversed design. Int Orthop. 2017;41:1227-34.

10. Wiesel BB, Gartsman GM, Press CM, Spencer EE, Morris BJ, Zuckerman JD, et al. What went wrong and what was done about it: pitfalls in the treatment of common shoulder surgery. J Bone Joint Surg Am. 2013;95:2061-70.

11. Loebenberg MI, Cuomo F. The treatment of chronic anterior and posterior dislocations of the glenohumeral joint and associated articular surface defects. Orthop Clin North Am. 2000;31:23-34.

12. Cheung E, Willis M, Walker M, Clark R, Frankle MA. Complications in reverse total shoulder arthroplasty. J Am Acad Orthop Surg. 2011;19(7):439-49.

13. Werner BS, Böhm D, Abdelkawi A, Gohlke F. Glenoid bone grafting in reverse shoulder arthroplasty for long-standing anterior shoulder dislocation. J Shoulder Elbow Surg. 2014;23(11):1655-61.

Cite this article as: Narayanan SK, Muthusamy N, Pauldhurai VK. Failed shoulder stabilization procedure in the elderly: reverse shoulder replacement is the treatment ultimum. Int J Res Orthop 2019;5:982-5. 